\title{
ASSESSMENT OF THE FRACTURE RESISTANCE OF NOVEL ZIRCONIA REINFORCED GLASS IONOMER IN COMPARISON TO NANO HYBRID RESIN COMPOSITE RESTORATIONS
}

\author{
Rehab Khalil Safy* and Heba Bahgat Abd Elmohsen*
}

\begin{abstract}
Objective: Evaluation of the influence of newly introduced Zirconia reinforced glass ionomer when used as a base or as a restorative material on fracture resistance and fracture pattern of class II restorations.

Methodology: Forty extracted, intact mandibular third molars with standardized MO cavities were randomly assigned into four groups according to the type restorative material: The control group was restored using nano hybrid resin composite (RC), Zirconia reinforced restorative glass ionomer group was used for restoring $\mathrm{Zr}$ group, resin modified glass ionomer cement as a base material below the resin composite restorations in RC/RMGI group and Zirconia reinforced restorative glass ionomer as a base material below the resin composite restorations in group $\mathrm{RC} /$ $\mathrm{Zr}$ group. After thermal cycling fracture resistance of the specimens was tested by the application of load in a universal testing machine. Fracture pattern of each specimen was also evaluated. Mean fracture resistance values for each group were calculated and compared using one way ANOVA $(P=0.05)$.
\end{abstract}

Results: The highest mean load necessary to fracture the specimens was found in RC/RMGI followed by $\mathrm{RC} / \mathrm{Zr}$ and $\mathrm{RC}$ groups respectively. While the lowest mean value was found in $\mathrm{Zr}$ group. The highest frequency of specimens' reparability was found in $\mathrm{Zr}$ group followed by $\mathrm{RC} /$ $\mathrm{Zr}$ and $\mathrm{RC}$ groups respectively. While the least frequency of reparability was found in RC/RMGI group.

Conclusions: Within the limitations of the current study, it could be concluded that despite higher fracture strength values of RMGIC as a base material below the resin composite restorations, clinicians might prefer using of Zirconomer Improved ${ }^{\circledR}$ as either a restoration or a base material as its fracture patterns are repairable.

KEY WORDS: Class II, Zirconomer Improved, resin modified glass ionomer cement, nano hybrid resin composite, fracture resistance, failure mode.

\footnotetext{
* Lecturer of Operative Dentistry, Faculty of Dentistry, Suez Canal University, Egypt
} 


\section{INTRODUCTION}

Posterior teeth are daily subjected to several factors that affect their fracture resistance. These factors involve long standing dental caries, trauma, non-carious lesions, extensive cavity preparations as well as root canal treatment. [1] Clinicians reported that Class II cavity preparations, especially if they involve both proximal surfaces, are shown to be a challenging situation. ${ }^{[2,3]}$ A wide variety of restorative modalities ranging from direct fillings using amalgam or resin composite to the more complex indirect restorations, each with its own challenges are indicated for the restoration of teeth with Class II cavities. ${ }^{[4]}$ All of the available restorative materials are concerned about reinforcing the fragile remaining tooth structure. ${ }^{[5-7]}$

One of the factors affecting the durability of the restorative material is their resistance to failure which is assessed by testing the material's fracture toughness. Fracture resistance is considered a quantitative way of expressing a material's resistance to fracture when a crack is already present. ${ }^{[8]}$ Therefore, the main concern of dental practitioners nowadays is how to improve the material's mechanical properties such as fracture toughness, bonding to tooth structures as well as compressive strength in order to increase their resistance to failure.

In recent years, materials with mechanical properties more similar to dentin (such as composites) have been preferred for restoring teeth. ${ }^{[9]}$ In the past few decades, resin composites were considered esthetically very important for restoration of posterior teeth especially in large MOD cavities. ${ }^{[10]}$ They expressed relatively low cost together with excellent esthetics relative to the full coverage and cast restorations. ${ }^{[11,12]}$ However, failure is seen among these materials as a result of excessive wear and polymerization shrinkage. ${ }^{[13]}$ Then, Glass ionomer cements were introduced to the dental market. Owing to their anticariogenicity, biocompatibility, and excellent adhesion to moist dentin, glass ionomers were considered for restoration of teeth especially in cases where resin composites were contraindicated.

Zirconomer Improved ${ }^{\circledR}$ is newly introduced high strength restorative material which appeared in the dental market as a substitute for the old dental amalgam with almost same strength together with being able to release fluoride like GICs. ${ }^{[14]}$ Besides, efforts were done by the manufacturers in order to overcome the defects present in the different types of tooth colored restorations such as conventional and resin modified glass ionomers as well as resin composites. This new modified version of glass ionomer is reinforced with Zirconia fillers. Zirconia is high strength ceramics with excellent esthetic properties and very good biocompatibility being metal free too. ${ }^{[15]}$ Owing to these advantages, these materials are thought to be the future restorative materials in dentistry. Therefore, it is a must to test their mechanical properties, as one of the objectives of a dental material is to fulfill all biological, mechanical, and esthetic requirements to be able to meet the demands of the oral cavity. Therefore, the aim of the present study was to evaluate the fracture resistance and the fracture mode of sound human mandibular molars restored with Zirconomer Improved ${ }^{\circledR}$ after thermal cycling.

\section{MATERIALS AND METHODS}

\section{Specimens' preparation}

Forty human impacted mandibular third molars freshly extracted for orthodontic treatment from patients in the age range 20-30 years were collected and cleaned. The inclusion criteria used for teeth selection included; sound teeth free of cracks, caries lesions, dental restorations, and any dental anomalies. Teeth showing old restorations or resorption were excluded from the study as well as open apices. The teeth were stored in buffered saline plus $0.5 \%$ thymol for not more than one month before testing. ${ }^{[16]}$ 
Teeth of similar size and shape have been chosen to minimize the impact of size and shape variations on the outcomes. The bucco-lingual and mesiodistal widths were measured in millimeters at the most prominent points of the crown with a digital caliper (SHAN, Japan). In order to prevent the use of outliers, teeth below or above the average size boundaries (mean $\pm \mathrm{SD}$ ) of $10.71 \pm 0.63 \mathrm{~mm}$ mesiodistally and $9.30 \pm 0.55 \mathrm{~mm}$ buccolingually were excluded. ${ }^{[17]}$

For mounting of chosen teeth on acrylic resin blocks, a cylindrical Teflon mold (15 mm diameter and $40 \mathrm{~mm}$ height) was used. The level of the acrylic resin was adapted $2 \mathrm{~mm}$ below the cementoenamel junction (CEJ) of each tooth with the help of a periodontal probe (UNC-15, Paterson Dental). ${ }^{[18]}$

\section{Cavity preparation}

Standardized occluso-mesial cavity (MO) was carried out with a diamond flat-ended fissure bur (Brasseler USA Dental, GA, USA) mounted in a high speed hand piece with copious air water spray in each specimen. In order to ensure standardization, a single operator prepared all the teeth at the same depth and width as possible with a digital caliper. All cavities' dimensions were standardized as follows: in each molar the bucco-lingual width of the occlusal portion of the cavity preparation was approximately one third of the bucco-lingual width of the tooth and $3 \mathrm{~mm}$ in depth. ${ }^{[19]}$ The preparation extended distally to include the triangular fossa, thereby maintaining marginal ridge of $1.6 \mathrm{~mm}$ thickness. ${ }^{[12]}$ The proximal box bucco-lingual width was the same as for the occlusal box without proximal flare and was located $1 \mathrm{~mm}$ coronal to the CEJ. ${ }^{[20]}$ Its axial depth was $2 \mathrm{~mm}$ and all the internal line angles were rounded. The cavo-surface angle in all the walls was 90 degrees. ${ }^{[20]}$ Teeth were held in buffered saline plus $0.5 \%$ thymol after cavity preparations until they were restored.

\section{Specimens grouping}

After complete cavities' preparation for all the specimens, teeth were divided randomly according to the restorative material used into four groups ( $n=10 /$ group). For restoration of the control group, nano hybrid resin composite (Filtek ${ }^{\mathrm{TM}}$ Z350 XT Nano Hybrid Universal Restorative, 3M ESPE) was used (RC). Meanwhile Zirconia reinforced restorative glass ionomer (Zirconomer Improved ${ }^{\circledR}$, Shofu INC, Japan) was used for restoring the Zr group. Resin modified glass ionomer cement (Vitrebond ${ }^{\mathrm{TM}}$ Plus Light Cured Glass Ionomer Liner/ Base, 3M ESPE) was used as a base material in RC/ RMGI group. For restoring teeth in $\mathrm{RC} / \mathrm{Zr}$ group, Zirconomer Improved was used as a base material. Then nano hybrid resin composite was used as a final restoration for restoring both of RC/RMGI and $\mathrm{RC} / \mathrm{Zr}$ groups.

For teeth restoration in all groups, a securely adjusted circumferential metal matrix (Automatrix ${ }^{\circledR}$ MT, Dentsply, Milford, DE, USA) encircled the prepared $\mathrm{MO}$ of each tooth. In order to clean up all the cavities from the remaining debris, light air water spray was used. For restoration of RC, RC/RMGI and $\mathrm{RC} / \mathrm{Zr}$ groups, two steps etch and rinse dentine bonding agent (Adper ${ }^{\mathrm{TM}}$ Single Bond 2 Adhesive, 3 M ESPE) was implemented in accordance with the manufacturer's instructions. Where $37 \%$ phosphoric acid etching gel (Meta Etchant, META BIOMED CO.LTD, Korea) was used to etch all occluso-mesial cavities, by firstly applying it to enamel for $15 \mathrm{~s}$, and then to the dentin for another $15 \mathrm{sec}$, rinsed with water for $15 \mathrm{~s}$ followed by blot drying using sponge. The Adper ${ }^{\mathrm{TM}}$ Single Bond 2 Adhesive was soaked in a disposable brush and then rubbed against the walls for $15 \mathrm{sec}$. To guarantee that the solvent is completely evaporated, a light air stream was used for $5 \mathrm{sec}$. The bonding agent was light cured with a standard $1200 \mathrm{~mW} / \mathrm{cm}^{2}$ actual irradiation output, and $440-490 \mathrm{~nm}$ for $20 \mathrm{~s}$ (Led Elipar ${ }^{\circledR} 3 \mathrm{M}$, ESPE) according to the manufacturer's instructions. After 
adhesive application A2 radiopaque light cured Filtek $^{\mathrm{TM}} \mathrm{Z} 350$ XT was used for restoration of the control group (RC). The resin composite was applied incrementally and adapted to the cavity walls using a ball and pear shape instrument. Each increment was then polymerized for $20 \mathrm{sec}$. where the light curing tip was maintained as close as possible to the restorative material. Post curing for $20 \mathrm{sec}$. of the buccal and lingual surfaces was carried out after removing the matrix band.

For restoration of the specimens of $\mathrm{Zr}$ Group, Zirconomer Improved ${ }^{\circledR}$ was used. According to the manufactures' instructions, two scoops of the powder and one liquid drop were dispensed on the mixing pad. The powder was dispensed into 2 equal portions, and then the first half was mixed with the liquid for 5-10 sec. with a plastic spatula, followed by mixing of the remaining half till thick putty-like consistency reached. This procedure was completed within a total of $30 \mathrm{sec}$. The prepared cavity of each tooth was rinsed with water and dried then; the mixture was filled in and shaped as desired. The surface of the final restoration was covered with cocoa butter (petroleum jelly) after removal of the matrix band.

For restoring RC/RMGI group the resin modified glass ionomer cement $\left(\right.$ Vitrebond $^{\mathrm{TM}}$ ) was manipulated according to the manufacturer's instructions and used as a base. Where, a small spatula was used for mixing the powder/liquid of the Vitrebond ${ }^{\mathrm{TM}}$ together for $10-15 \mathrm{sec}$. until smooth consistency and glossy appearance achieved. Using a very small ball applicator the paste was applied to the pulpal floor and the axial wall from the level of the gingival floor up to the level of the pulpal floor, the material was then cured with light for 20 sec. For restoring $\mathrm{RC} / \mathrm{Zr}$ group, the Zirconomer improved was used as base material in each cavity. The material was mixed according to manufactures' instructions as previously mentioned, and then it was applied to the pulpal floor and also to the axial wall. Following the base material application procedures in both of $\mathrm{RC} / \mathrm{RMGI}$ and $\mathrm{RC} / \mathrm{Zr}$ groups, the entire cavity preparations were treated with the two steps etch and rinse adhesive. Then the cavities were restored with nano hybrid resin composite (Filtek ${ }^{\mathrm{TM}} \mathrm{Z} 350 \mathrm{XT}$ ) using the incremental technique as discussed before for the control group. Materials used in this study are shown in Table 1.

\section{Thermal cycling}

All restored specimens were thermocycled for 1000 cycles. They were immersed in water bath at $5^{\circ} \mathrm{C}$ followed by $55^{\circ} \mathrm{C}$ for 20 seconds dwell time each, with an intermediary $5 \mathrm{sec}$. resting time (Thermo-cycling apparatus Mechatronic, Germany).

\section{Fracture Resistance Test}

The specimens were subjected to a fracture test (Instron, Universal Testing Machine, Model 3345 England) for evaluation of the fracture resistance of all groups. A modified steel indenter with a diameter of $3 \mathrm{~mm}$ was customized to apply compression mode of loading of 5000 Newton load cell with a crosshead speed of $1 \mathrm{~mm} / \mathrm{min}$ up to specimen failure. The load at the specimen fracture was recorded in newton and analyzed. Failure manifested by first crack sound initiation and confirmed by sudden drop of loaddeflection curve recorded with computer software (Blue Hill Instron).

\section{Fracture mode assessment}

After failure, all the specimens were visually inspected and photo-micro- graphed by the aid of digital camera mounted on stereo microscope(Nikon MA100, Japan) at $25 \mathrm{x}$ to evaluate the fracture mode. ${ }^{[21]}$ Fracture patterns were identified mainly in 4 types: ${ }^{[22]}$ Type I: Cusp or composite resin fracture above the CEJ was considered to be repairable, type II: Vertical fracture at one or two cusps that did not extend into the root and was considered to be repairable, type III: Vertical fracture at one or two 
cusps below the CEJ extending into the root and was considered to be non-repairable and type IV: Vertical longitudinal fracture dividing the crown into 2 pieces extending into the root or bifurcation and was non repairable.

\section{Statistical analysis}

Parametric tests were used for comparison between groups in the fracture resistance test. One-way ANOVA followed by Tukey post hoc test was used to compare between more than two groups in non-related samples. Data were explored for normality in the fracture mode test using Kolmogorov-Smirnov and Shapiro-Wilk tests, data showed non-parametric (not-normal) distribution. Kruskal Wallis test was used to compare between more than two groups in non-related samples. Mann Whitney was used to compare between two groups in non-related samples. The significance level was set at $\mathrm{P} \leq 0.05$ for both tests. Statistical analysis was performed with IBM® SPSS ${ }^{\circledR}$ Statistics Version 20 for Windows.

\section{RESULTS}

\section{Fracture resistance results}

The highest mean load necessary to fracture the specimens was found in RC/RMGI followed by RC/ $\mathrm{Zr}$ and RC groups respectively. While the lowest mean value was found in $\mathrm{Zr}$ group. A statistically significant difference was found between $\mathrm{RC}, \mathrm{Zr}$, $\mathrm{RC} / \mathrm{RMGI}$ and $\mathrm{RC} / \mathrm{Zr}$ group where $(\mathrm{p}<0.001)$.

TABLE (1): Materials' Description, Composition, Manufacturers and Batch numbers.

\begin{tabular}{|c|c|c|c|c|}
\hline Materials & Description & Composition & Manufacturers & $\begin{array}{c}\text { Batch } \\
\text { number }\end{array}$ \\
\hline $\begin{array}{l}\text { Zirconomer } \\
\text { Improved }^{\circledR}\end{array}$ & $\begin{array}{l}\text { Zirconia } \\
\text { reinforced } \\
\text { restorative } \\
\text { glass ionomer }\end{array}$ & $\begin{array}{l}\text { Powder: aluminofluoro-silicate glass, zirconium ox- } \\
\text { ide, tartaric acid } \\
\text { Liquid: polyacrylic acid, deionized water }\end{array}$ & $\begin{array}{l}\text { (Shofu INC, } \\
\text { Japan) }\end{array}$ & 03171480 \\
\hline $\begin{array}{c}\text { Filtek }^{\mathrm{TM}} \mathrm{Z350} \\
\text { XT Universal } \\
\text { Restorative }\end{array}$ & $\begin{array}{l}\text { Nano- } \\
\text { hybrid resin } \\
\text { composite }\end{array}$ & $\begin{array}{l}\text { Filler system: Surface-modified zirconia/silica with } \\
\text { a median particle size of approximately } 3 \text { microns or } \\
\text { less. Non-agglomerated/non-aggregated } 20 \text { nanometer } \\
\text { surface-modified silica particles. The filler loading is } \\
82 \% \text { by weight ( } 68 \% \text { by volume } \\
\text { Matrix System: BIS-GMA, UDMA, BIS-EMA, } \\
\text { PEGDMA and TEGDMA }\end{array}$ & \multirow{3}{*}{ 3M ESPE } & N721306 \\
\hline $\begin{array}{l}\text { Vitrebond }{ }^{\mathrm{TM}} \text { Plus } \\
\text { Light Cure Glass } \\
\text { Ionomer Liner/ } \\
\text { Base. }\end{array}$ & $\begin{array}{l}\text { Resin } \\
\text { modified } \\
\text { glass ionomer } \\
\text { cement }\end{array}$ & $\begin{array}{l}\text { Liquid: polyalkenoic acid, HEMA } \\
\text { (2-hydroxyethymethacrylate), water and initiators } \\
\text { (including camphorquinone) } \\
\text { Paste: HEMA, BIS-GMA, water, initiators and a } \\
\text { radiopaque fluoroaluminosilicate glass (FAS glass). }\end{array}$ & & 1806061 \\
\hline $\begin{array}{l}\text { Adper }{ }^{\mathrm{TM}} \text { Single } \\
\text { Bond } 2 \text { Adhesive }\end{array}$ & $\begin{array}{l}\text { Two step, } \\
\text { etch and rinse } \\
\text { adhesive } \\
\text { system }\end{array}$ & $\begin{array}{l}\text { BisGMA, HEMA, dimethacrylates, ethanol, water, } \\
\text { a novel photoinitiator system and a methacrylate } \\
\text { functional copolymer of polyacrylic and polyitaconic } \\
\text { acids }\end{array}$ & & N716057 \\
\hline Meta Etchant & Etching gel & $\begin{array}{l}\text { Non-dripping gel consistency, } 34.9 \% \text { phosphoric acid, } \\
\text { Blue color for visual control. }\end{array}$ & $\begin{array}{l}\text { META } \\
\text { BIOMED Co. } \\
\text { LTD, Korea }\end{array}$ & 151005 \\
\hline
\end{tabular}


A statistically significant difference was found between the control group ( $\mathrm{RC}$ ) and each of $\mathrm{RC} /$ RMGI and $\mathrm{RC} / \mathrm{Zr}$ groups where $(\mathrm{p}<0.001)$ and $(\mathrm{p}<0.001)$ respectively, while no statistically significant difference was found between $\mathrm{RC}$ and $\mathrm{Zr}$ groups where $(\mathrm{p}=0.998)$. A statistically significant difference was found between $\mathrm{Zr}$ group and each of $\mathrm{RC} / \mathrm{RMGI}$ and $\mathrm{RC} / \mathrm{Zr}$ groups where $(\mathrm{p}<0.001)$ and $(\mathrm{p}<0.001)$ respectively, A statistically significant difference was found between RC/RMGI and RC/ Zr where $(\mathrm{p}<0.001)$.

TABLE (2): Fracture resistance mean and standard deviation (SD) in different groups.

\begin{tabular}{|c|c|c|}
\hline \multirow{2}{*}{ Variables } & \multicolumn{2}{|c|}{ Fracture resistance } \\
\hline & Mean & SD \\
\hline RC & 2545.21 & 122.29 \\
\hline $\mathbf{Z r}$ & 2536.30 & 256.65 \\
\hline RC/RMGI & 4325.76 & 238.11 \\
\hline $\mathbf{R C} / \mathbf{Z r}$ & 3032.47 & 10.13 \\
\hline p-value & \multicolumn{2}{|c|}{$<0.001 *$} \\
\hline
\end{tabular}

*; significant $(p<0.05) n s ;$ non-significant $(p>0.05)$

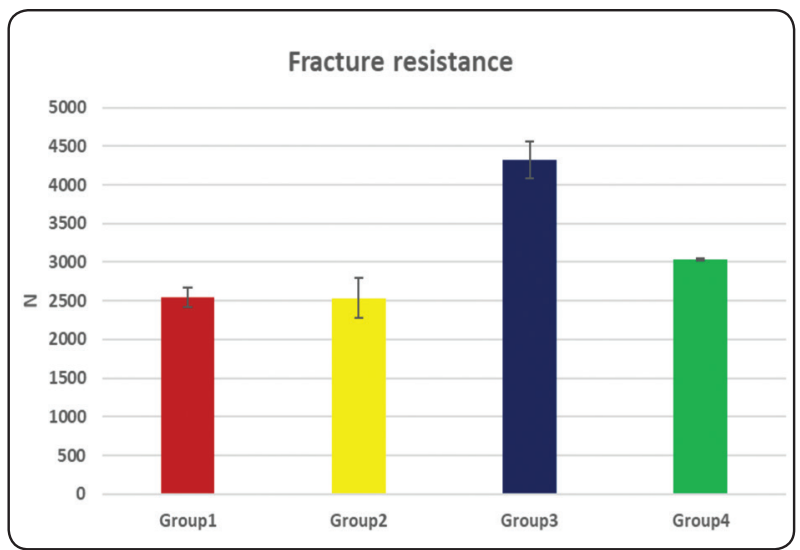

Fig. (1): Bar chart representing the fracture resistance for different groups

\section{Fracture mode results}

The highest frequency of reparability was found in $\mathrm{Zr}$ group followed by $\mathrm{RC} / \mathrm{Zr}$ and $\mathrm{RC}$ groups respectively, while the least frequency of reparability was found in RC/RMGI group. A statistically significant difference was found between $\mathrm{RC}, \mathrm{Zr}, \mathrm{RC} /$ RMGI and $\mathrm{RC} / \mathrm{Zr}$ groups where $(p=0.005)$. A statistically significant difference was found between $\mathrm{RC}$ and $\mathrm{Zr}$ groups where $(\mathrm{p}=0.028)$, while no statistically significant difference was found between $\mathrm{RC}$ group and each of $\mathrm{RC} / \mathrm{RMGI}$ and $\mathrm{RC} / \mathrm{Zr}$ groups where $(p=0.276)$ and $(p=0.081)$ respectively. A statistically significant difference was found between $\mathrm{Zr}$ group and RC/RMGI group where $(\mathrm{p}=0.002)$. While no statistically significant difference was found between $\mathrm{Zr}$ group and $\mathrm{RC} / \mathrm{Zr}$ group where $(p=0.615)$. Also a statistically significant difference was found between $\mathrm{RC} / \mathrm{RMGI}$ and $\mathrm{RC} / \mathrm{Zr}$ groups where $(p=0.008)$.

TABLE (3): Fracture mode frequencies of different groups.

\begin{tabular}{|c|c|c|c|}
\hline \multirow{2}{*}{ Variables } & \multirow{2}{*}{ ariables } & \multicolumn{2}{|c|}{ Fracture mode } \\
\hline & & $\mathbf{n}$ & $\%$ \\
\hline \multirow{2}{*}{ RC } & Repairable & 3 & $30 \%$ \\
\hline & Non-Repairable & 7 & $70 \%$ \\
\hline \multirow{2}{*}{$\mathbf{Z r}$} & Repairable & 8 & $80 \%$ \\
\hline & Non-Repairable & 2 & $20 \%$ \\
\hline \multirow{2}{*}{ RC/RMGI } & Repairable & 1 & $10 \%$ \\
\hline & Non-Repairable & 9 & $90 \%$ \\
\hline \multirow{2}{*}{$\mathbf{R C} / \mathbf{Z r}$} & Repairable & 7 & $70 \%$ \\
\hline & Non-Repairable & 3 & $30 \%$ \\
\hline \multicolumn{2}{|l|}{ p-value } & \multicolumn{2}{|c|}{$0.004 *$} \\
\hline
\end{tabular}

*; significant $(p<0.05) n s ;$ non-significant $(p>0.0$ 


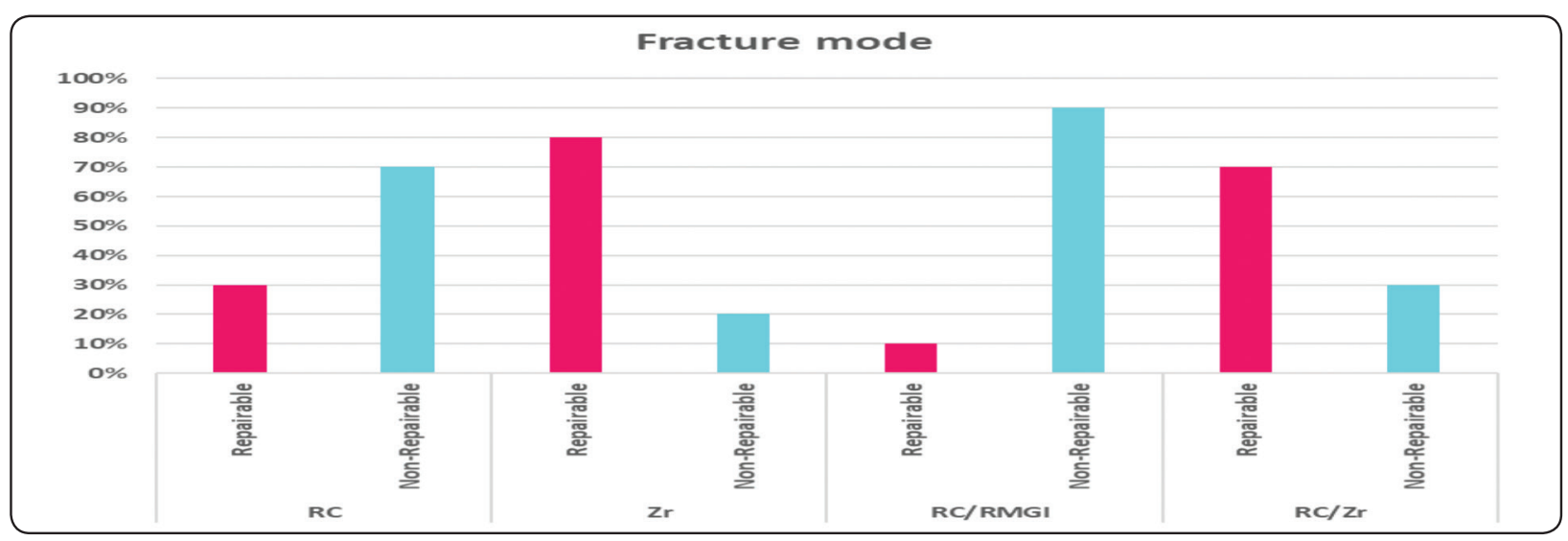

Fig. (2): Bar chart representing fracture mode for different groups

\section{DISCUSSION}

Conventional GICs have low wear resistance and marginal integrity and are frequently quoted as a reason for excluding them for restoration of stress-bearing areas. Manufacturers conducted multiple studies for achieving superior mechanical characteristics, such as high flexural modulus and compressive strength, improved structural integrity of the glass ionomer restorations with durability and continuous fluoride release in patients with high caries risk. ${ }^{23,24]}$ Addition of multiple fillers like gold, silver, palladium, titanium, zirconia, stainless steel powder and $\mathrm{SiC}$ whiskers into glass ionomers was explored to enhance their mechanical properties, but their considerable constraints are low esthetic and low abrasion resistance. [25, 26] Zirconia fillers were often implemented owing to their chemical and good mechanical strength in dental procedures like implants. Zirconia is one of the tooth-colored materials with good dimensional stability and excellent strength and is the origin of the interest in using $\mathrm{ZrO} 2$ as filler. ${ }^{27,28]}$

Zirconomer is zirconia reinforced glass ionomer cement, which the manufacturer claims to display superior mechanical properties while maintaining the capacity for release of fluoride of GICs. ${ }^{[14]}$ According to the Zirconomer $^{\circledR}$ (white amalgam) company, it exhibits strength consistent with amalgam and is more esthetically acceptable, through a rigorous manufacturing technique. In order to attain optimum particle size and characteristics, the glass components of this high-resistance ionomer undergoes fine controlled micronization. ${ }^{[29]}$ Zirconia particles have been homogenously incorporated into the glass element to further strengthen the material for long lasting durability and high tolerance to occlusal load. Polyalkenic acid and glass elements were also specially processed to convey to this high-strength glass ionomer superior mechanical handling qualities. ${ }^{[29-34]}$

Anew class of restorative material Zirconomer Improved $^{\circledR}$ is created as a reliable and durable self-adhesive tooth colored zirconia reinforced posterior restorative. In contrast to Zirconomer ${ }^{\circledR}$, novel nano-sized zirconia fillers was incorporated to increase the material translucency for a shade nearer to natural tooth, with superior handling characteristics for easy, quick and easy application in bulk. Zirconomer Improved ${ }^{\circledR}$ was claimed by the company to be ideal as a bulk fill restoration for structural cores and bases. Also they claimed that it outperforms well in high caries risk cases with high compressive strength, dimensional stability and long-lasting performance as restorations of stressbearing areas where the conventional restorative of choice is amalgam. ${ }^{[14,35]}$

A significant factor in the long-lasting performance of the restorative system is the fracture 
resistance of the restorative material. This characteristic feature is the resistance of the restorative material to intraoral compressive and tensile forces generated in function and parafunction. Therefore, excellent compressive strength is crucial for the restorative material. The test of compressive strength is often used to predict the efficiency of a restorative material in the oral environments by clinicians and scientists. ${ }^{[36]}$

Thermo-cycling is considered a common in vitro aging technique simulating the intake of hot and cold beverages and food in the daily life. In the current study, thermo-cycling was carried out to try to mimic what happens intraorally to a great extent. Since, 10,000 cycles are equivalent to 1 year of intra oral performance. ${ }^{[37]}$ Therefore, subjecting the specimens in the present study to 1000 cycles representing approximately1.2 months of in vivo activity.

The result of the current study found that the compressive strength of Zirconomer Improved $^{\circledR}$ (Zr) group does not differ statistically significantly with the nano hybrid resin composite (RC) group. This finding could be ascribed to the reinforcement of the material with the nano-zirconia fillers that is responsible for imparting enhanced mechanical properties especially making it suitable for posterior load bearing areas. ${ }^{[14,36]}$

The specimens restored with RMGIC as a base material in RC/RMGI group, recorded the highest mean of compressive strength, followed by $\mathrm{RC} / \mathrm{Zr}$ group in which the specimens were also restored using Zirconomer Improved ${ }^{\circledR}$ as a base material. This finding can be clarified by the use of glass ionomer in $\mathrm{RC} / \mathrm{RMGI} \& \mathrm{RC} / \mathrm{Zr}$ groups, which can alleviate the stresses of polymerization shrinkage, as a base material with low-elastic modulus. ${ }^{[38,39]}$ Where on the basis of the low elastic modulus and high wettability of flowable materials relative to conventional composites, the researchers developed the concept of an "elastic wall" or "elastic bonding" and recommended to apply flowable materials as a base layer. ${ }^{[40,41]}$ This kind of base material can not only absorb the shrinkage stresses when the composite resins are polymerized in situ, but also the stress of the functional load on the restored tooth. Since the effectiveness of the base layer at absorbing stresses depends on its thickness and elastic modulus, it is possible to attribute the statistically significant difference between $\mathrm{RC} /$ RMGI \& RC/Zr groups to the low modulus of elasticity of the Vitrebond ${ }^{\mathrm{TM}}$ restorative material in comparison to the Zirconomer Improved ${ }^{\circledR}$ that resulting in better relief of stresses in specimens restored with Vitrebond ${ }^{\mathrm{TM}}$ as an base restorative material. ${ }^{[15,42]}$ Also this result could be attributed to the low bond strength that exists between zirconia-reinforced glass ionomer and the resin composite, which results in an insufficient bonded surface owing to lack of resin in its composition. Therefore, Zirconomer Improved ${ }^{\circledR}$ registered lower fracture resistance when used as base material when compared with the RMGIC. ${ }^{[43]}$

The fracture mode distribution was therefore assessed in this research owing to its key role in the restoration status assessment. The condition of the restoration significantly affects the decision to be taken to either repair or replace it. Dental practitioners recorded repair as an authorized technique in enhancing the dental restoration's durability being much more conservative than complete replacement. [44] The results of the current study have shown that using of zirconomer improved $^{\circledR}$ in $\mathrm{Zr}$ and $\mathrm{RC} / \mathrm{Zr}$ groups have shown the best results regarding the fracture mode with $80 \%$, $70 \%$ repairable fracture respectively. In addition to the aforementioned benefits of Zirconium Improved ${ }^{\circledR}$ restorations, this result might be explained through the unique micronization of its glass particles to produce particle size homogeneity which enables the material to resist occlusal load. ${ }^{[29]}$ It worth mentioning that, RC/RMGI showed presented a larger number of catastrophic fractures with $90 \%$ non-repairable fracture mode. Meanwhile, the behavior of RC restorations was unpredictable, upon 
being subjected to forces, $70 \%$ of the restoration showed non repairable fractures. However, further in vitro and in vivo studies are necessary to confirm the results of the current study.

\section{CONCLUSION}

Within the limitations of the current study, it could be concluded that despite higher fracture strength values of RMGIC as a base material below the resin composite restorations, clinicians might prefer using of Zirconomer Improved ${ }^{\circledR}$ as either a restoration or a base material as its fracture patterns are repairable.

\section{REFERENCES}

1. Wu MK, van der Sluis LW, Wesselink PR. Comparison of mandibular premolars and canines with respect to their resistance to vertical root fracture. J Dent 2004; 32:265- 8 .

2. Krämer N, Reinelt C, Frankenberger R. Ten-year clinical performance of posterior resin composite restorations. $\mathrm{J}$ Adhes Dent 2015;17:433-41.

3. Pallesen U, van Dijken JW. A randomized controlled 30 years follow up of three conventional resin composites in class II restorations. Dent Mater 2015;31:1232-44.

4. Christensen GJ. Longevity of posterior tooth dental restorations. J Am Dent Assoc 2005;136:201-3.

5. Nam SH, Chang HS, Min KS, Lee Y, Cho HW, Bae JM, et al. Effect of the number of residual walls on fracture resistances, failure patterns, and photoelasticity of simulated premolars restored with or without fiber-reinforced composite posts. J Endod 2010;36:297-301.

6. Meng QF, Chen YM, Guang HB, Yip KH, Smales RJ. Effect of a ferrule and increased clinical crown length on the in vitro fracture resistance of premolars restored using two dowel-and-core systems. Oper Dent 2007;32:595-601.

7. Soares PV, Santos-Filho PC, Martins LR, Soares CJ. Influence of restorative technique on the biomechanical behavior of endodontically treated maxillary premolars. Part I: Fracture resistance and fracture mode. J Prosthet Dent 2008;99:30-7.

8. Prabhakar AR, Paul M J, Basappa N. Comparative Evaluation of the Remineralizing Effects and Surface Micro hardness of GlassIonomer Cements Containing Bioactive
Glass (S53P4):An in vitro Study. Int J Clin Pediatr Dent. 2010;3:69-77.

9. Eskitaşcioğlu G, Belli S, Kalkan M. Evaluation of two post core systems using two different methods (fracture strength test and a finite elemental stress analysis). J En$\operatorname{dod} 2002 ; 28: 629-33$.

10. Sadowsky SJ. An overview of treatment considerations for aesthetic restorations: a review of the literature. J Prosthet Dent 2006; 96:433-442.

11. Mondelli RF, Ishikiriama SK, de Oliveira Filho O, Mondelli J. Fracture resistance of weakened teeth restored with condensable resin with and without cusp coverage. J Appl Oral Sci 2009; 17:161-5.

12. Plotino G, Buono L, Grande NM, Lamorgese V, Somma F. Fracture resistance of endodontically treated molars restored with extensive composite resin restorations. J Prosthet Dent 2008; 99:225-32.

13. Christensen GJ. Buonocore memorial lecture. Tooth-colored posterior restorations. Oper Dent. 1997;22(4):146148.

14. http://www.shofu.com.sg/downloads/pdf/Zirconomer\%20 Brochure.pdf.

15. Abdulsamee $\mathrm{N}$ and Elkhadem $\mathrm{AH}$. Zirconomer and Zirconomer Improved (White Amalgams): Restorative Materials for the Future. Review. EC Dental Science 15.4 (2017): 134-150.

16. Dere $M$, Özcan $M$ and Göhring: N Marginal quality and fracture strength of root-canal treated mandibular molars with overlay restorations after thermo-cycling and mechanical loading. J Adhes Dent; 12: 287-294, 2010.

17. Rodrigues F. B, Paranhos, Spohr M, Oshima H, and Burnett Jr: Fracture resistance of root filled molar teeth restored with glass fibre bundles. Int Endod J; 43, 356-362, 2010.

18. Oskoee P, Amir Ahmad Ajami A, Navimipour E, Oskoee S, and Sadjadi J: The effect of three composite fiber insertion techniques on fracture resistance of root-filled teeth. J Endods; 35:413-416, 2009.

19. López S, Sanz Chinesta M, Ceballos L García, Gasquet F, Rodríguez M. Influence of cavity type and size of composite restorations on cuspal flexure. Med Oral Patol Oral Cir Bucal 2006;11:E536-40.

20. Mohammadi N, Kahnamoii M, Yeganeh P, \& Navimipour E. Effect of fiber post and cusp coverage on fracture resistance 
of endodontically treated maxillary premolars directly restored with composite resin. J Endods; 35:1428-1432, 2009.

21. Moezizadeh M, Shokripour M: Effect of fiber orientation and type of restorative material on fracture strength of the tooth. J Conserv Dent; 14(4): 341-345, 2011.

22. Akman S, Akman M, EskitasciogluG, Belli S: Influence of several fibre-reinforced composite restoration techniques on cusp movement and fracture strength of molar teeth. Int Endodontic J; 44:407-415, 2011.

23. Ten Cate JM, Van Duinen RNB. Hypermineralization of dentinal lesions adjacent to glass-ionomer cement restorations. J. Dent. Res. 1995;74:1266-1271.

24. Mount GJ. Clinical performance of glassionomers. Biomaterials. 1995;54(19):573-579.

25. Lee JJ., et al. "Physical properties of resin-reinforced glass ionomer cement modified with micro and nano-hydroxyapatite". Journal for Nanoscience and Nanotechnology2010 (10.8): 5270-5276.

26. Sharafeddin F., et at. The Effect of Adding Glass and Polyethylene Fibres on Flexural Strength of Three Types of Glass-Ionomer Cements". Research Journal of Biological Sciences 8.3 (2013): 66-70.

27. Khoroushi M., et al. "Effect of resin-modified glass ionomer containing bioactive glass on the flexural strengthand morphology of demineralized dentin. Oper Dent 2013 (38.2): E1-E10.

28. Li HC., et al. "Effect of $\mathrm{ZrO}$ additions on the crystallization, mechanical and biological properties of $\mathrm{MgO}-\mathrm{CaO}-\mathrm{SiO}_{(2)}$ $\mathrm{P}(2) \mathrm{O}_{(5)}-\mathrm{CaF}_{(2)}$ bioactive glass-ceramics". Colloids and Surfaces B: Biointerfaces 2014 (118): 226-233.

29. Haragopal S, Sreeramulu B, Shalini K, Sudha MD, Kiran G. Zirconia: A credible restorative material-A review. Ann Essences Dent 2012;4:63-5.

30. Khamverdi Z, Moshiri Z. Zirconia: An up-to-date literature review. Avicenna J Dent Res 2012; 4:1-15.

31. Gu YW, Yap AU, Cheang P, Khor KA. Effects of incorporation of $\mathrm{HA} / \mathrm{ZrO}(2)$ into glass ionomer cement (GIC). Biomaterials $2005 ; 26: 713-20$.

32. Piconi C, Maccauro G. Zirconia as a ceramic biomaterial. Biomaterials 1999;20:1-25.
33. Hickel R, Manhart J. Longevity of restorations in posterior teeth and reasons for failure. J Adhes Dent 2001;3:45-64.

34. Chalissery VP, Marwah N, Almuhaiza M, AlZailai AM, Chalisserry EP, Bhandi SH, et al. Study of the mechanical properties of the novel zirconia-reinforced glass lonomer cement. J Contemp Dent Pract 2016;17:394-8.

35. Prabhakar AR, Kalimireddy P, Yavagal C, Sugandhan S. Assessment of the clinical performance of zirconia infused glass ionomer cement: An in vivo study. Int J Oral Health Sci 2015; 5:74-9.

36. FDA. "Dental devices: Classification of dental amalgam, reclassification of dental mercury, designation of special controls for dental amalgam, mercury, and amalgam alloy. Final rule”. Federal Register2009 (74): 38685-38714.

37. Gale MS, Darvell BW. Thermal cycling procedures for laboratory testing of dental restorations. J Dent, 1999; 27(2)89-99.

38. Olliveira LC, Duarte S Jr, Araujo CA, Abrahão A. Effect of low-elastic modulus liner and base as stress-absorbing layer in composite resin restorations. Dent Mater 2010; 26: 159- 169.

39. Braga RR, Hilton TJ, Ferracane JL. Contraction stress of flowable composite materials and their efficacy as stressrelieving layers. J Am Dent Assoc 2003; 134: 721-728.

40. Kemp-Scholte CM, Davidson CL. Marginal integrity related to bond strength and strain capacity of composite resin restorative systems. J Prosthet Dent 1990; 64: 658-664.

41. Cavalcanti AN, Mitsui FH, Ambrosano GM, Marchi GM. Influence of adhesive systems and flowable composite lining on bond strength of class II restorations submitted to thermal and mechanical stresses. J Biomed Mater Res B Appl Biomater 2007; 80: 52-58.

42. https://multimedia.3m.com/mws/media/46320O/3m-vitrebond-glass-ionomer-liner-base-techn

43. Arora V, Kundabala M, Parolia A, Thomas MS, Pai V. Comparison of the shear bond strength of RMGIC to a resin composite using different adhesive systems: an in vitro study. $\mathrm{J}$ Conserv Dent 2010; 13: 80-83.

44. Hickel R, Brüshaver K, Ilie N. Repair of restorations - Criteria for decision making and clinical recommendations. Dent Mater 2013; 29:28-50. 